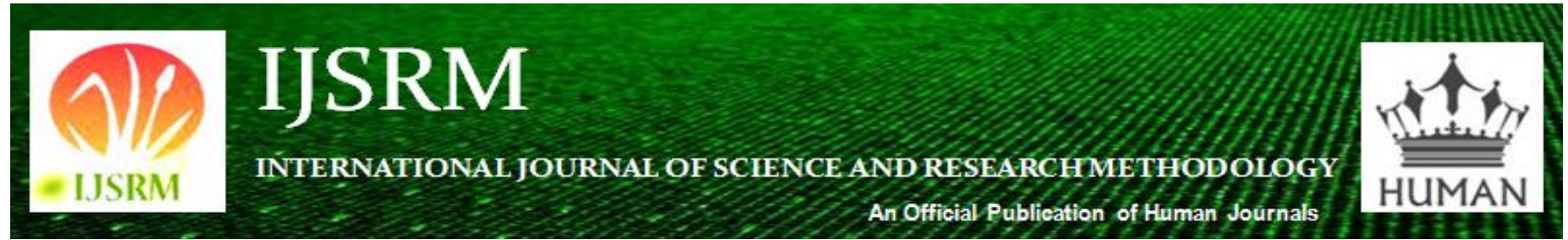

Human Journals

Review Article

September 2020 Vol.:16, Issue:3

(C) All rights are reserved by Muhammad Awais et al.

\title{
Role of Stem Cells in Autistic Spectrum Disorder (ASD); Can it Change the Future?
}

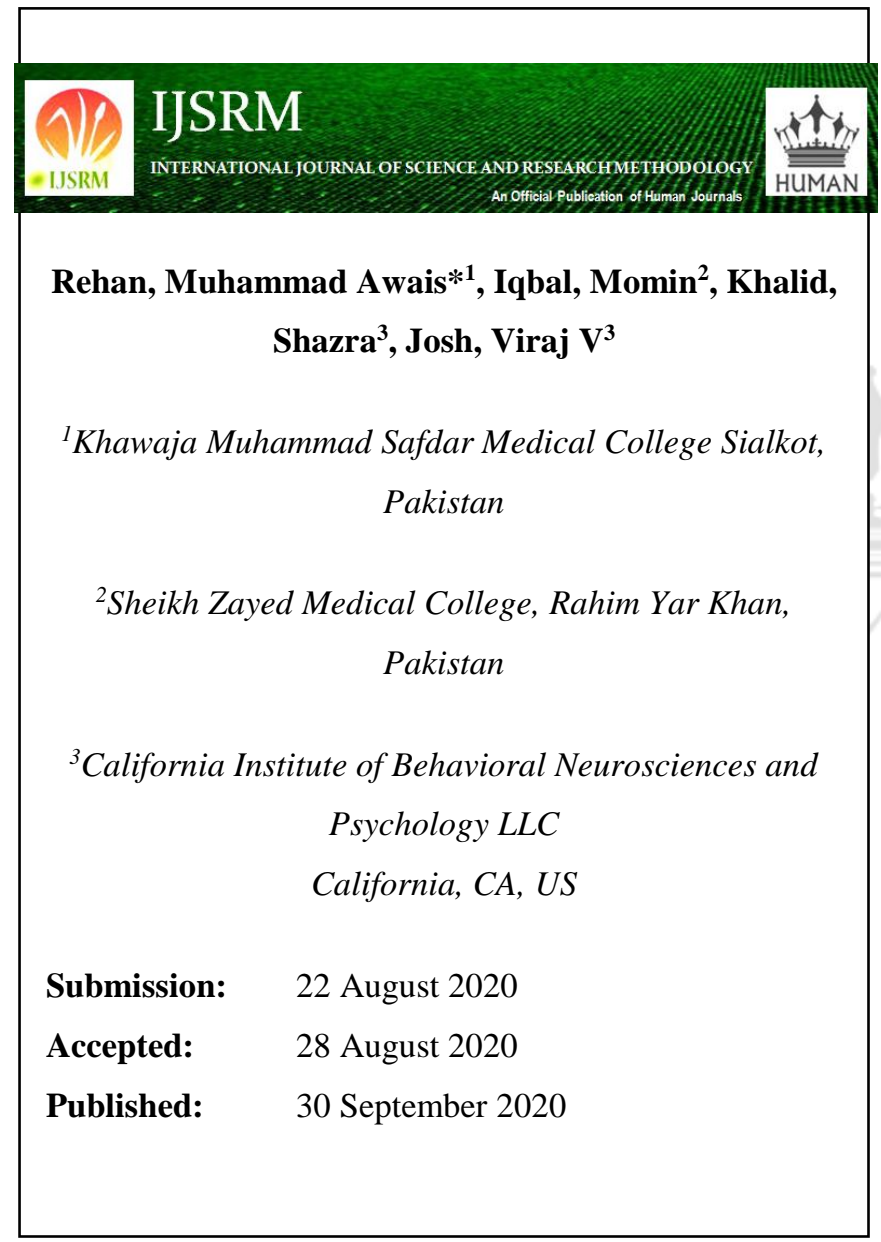
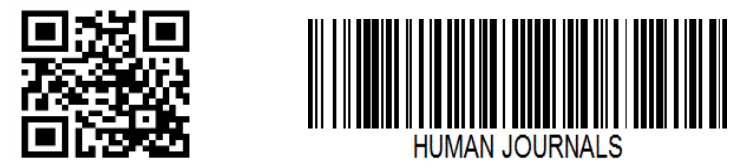

www.ijsrm.humanjournals.com
Keywords: "stem cell therapy and autism"; "stem cell therapy and autistic spectrum disorder"; "stem cells and autistic spectrum disorder"; "stem cells and autism"; "induced pluripotent stem cells and autistic spectrum disorder"; "induced pluripotent stem cells and autism"

\section{ABSTRACT}

Autistic spectrum disorder (ASD) is a group of disorders described by disabled social connection and serotyped conduct, interests and activities causing gross functional impedance. The precise pathogenesis, etiology, genetic involvement, and treatment are as yet under study. The absence of accessibility of live patient-particular neurons has been a substantial limitation in contemplating ASD pathophysiology. The ongoing utilization of induced pluripotent stem cells (iPSCs) to produce the human neurons from somatic cells, has altered the field of research for better understanding the distinctive aspects of ASD. In this article, we featured the fundamental properties of stem cells, conceivable sources, gene articulation, differentiation pattern, immune-modulatory impacts, safety issues and route of administration. We likewise talked about conceivable mechanisms of pathogenesis, i.e. changes in neural structure, genetic variability, molecular varieties, immune hyperactivity state and hypo-perfusion of the brain. Remedial intercessions concerning drug screening and transplantation treatment in the various setting have additionally been assessed, quickly. 


\section{INTRODUCTION}

Autism spectrum disorder, as characterized in the DSM $-5^{1}$ alludes to four previously distinctive neurodevelopmental diagnoses including autism, Asperger syndrome, childhood disintegrative disorder, and pervasive developmental disorder-not otherwise specified (PDD-NOS). Syndromic forms of ASD contain disorders with a known, usually monogenetic, cause including fragile $\mathrm{X}$ syndrome (FXS), Timothy syndrome (TS), cyclin-dependent kinase-like 5 disorder, and Rett syndrome (RTT). Conversely, non-syndromic, or idiopathic, forms of autism, do not have a known genetic etiology. It usually presents at the age of 2 years with a child lacking behind the standard growth curve and unfit to achieve normal reflexes and skills(e.g., some patients do not express social smile) ${ }^{2}$. The cause of ASD is obscure and making it challenging for disclosure of appropriate cure for the disease. The U.S. Food and Drug Administration presently cannot seem to favor a single drug for the treatment of autism's core symptoms. There is no diagnostic test available $^{3}$. At present accessible treatments for autism can be divided into behavioral, nutritional, and pharmacological options, in addition to individual and family psychotherapy and other nonpharmacologic remedies ${ }^{4}$. Psycho-stimulants, alpha-2 agonists, beta blockers, lithium, anticonvulsant mood stabilizers, atypical antipsychotics, traditional antipsychotics, selective serotonin reuptake inhibitors, antidepressants, and antipsychotics, are drugs commonly prescribed $^{5-7}$. Catatonia is treated with lorazepam and bilateral electroconvulsive therapy ${ }^{8}$.

In spite of the disclosure of many proposed mechanisms explaining neuron's structural changes, genetic transformations, molecular modifications and impact of environmental factors engaged with the pathogenesis of ASD, the research in this field still need good endeavors in uncovering the truth behind this myth. Sir John Gordon and Shinya Yamanaka have just been granted the Nobel Prize in 2012 for Medicine on their contribution to the reprogramming technology and featuring the noteworthiness of this logical breakthrough ${ }^{9}$. Since at that point, (iPSCs) have pulled in consideration of researchers, policymakers, and ethicists due to their mysterious properties. The utilization of iPSCs for understanding the pathogenesis, drug screening, and restorative perspectives has revolutionized the field of research. Now; we are a step closer for the accomplishment of desired objectives concerning the management of ASD patients. In this review, we are looking into the different aspect of stem cells utilization from various sources in 
understanding the pathogenesis, diagnostics, drug testing, and therapeutic transplantation, giving likely outcomes.

1 in 68 children and is said to be the fastest-growing serious developmental disability in the United States $^{3}$. Through the endeavors of autism advocacy groups, ASD is presently viewed as a national health priority in the United States, with government and private subsidizing more than $\$ 400$ million in $2010^{10}$. In this review, we assembled data from different research articles to assess the exact role of (iPSCs) for providing a path to future researchers to recognize the advantages and disadvantages of (iPSCs) used for the helpfulness of ASD patients. We additionally assess the accessible sources of stem cells, routes of delivery, and follow up of results from different patient and advances made in drug screening and transplantation choices, consequently, presumed that there is a promising future for ASD people. Various highlights with respect to the application in large-scale cohort study are as yet inaccessible. A number of key troubles remain, including the scaling of iPSC models to bigger companions and joining with rich clinicopathological information and translation of phenotypes ${ }^{11}$. Large-scale screening of chemical libraries with disease-specific iPSCs and their utilization in drug testing and transplantation may give us an exceeding expectation. In light of the way that the use of iPSC innovation in disease modeling requires a known disease phenotype for exhibit of the cell model; autism research including this innovation centers around monogenic cases, for instance, Rhett Disorder, Fragile X Disorder, and Timothy Syndrome, which involve only $15 \%$ of every single dissected case $\mathrm{e}^{12-15}$. However, a superior future can be expected for an ASD individual by the assistive advancements made by iPSCs in the field of analytic and remedial Medicine.

\section{METHOD AND SEARCH CRITERIA:}

\section{Source of data collection:}

Do the stem cells have any role in exploring the pathogenesis, diagnosis, and management of autism? With this question in mind, the data was searched and collected. Top online databases (PubMed etc.) mainly were utilized as a source of data collection. We included only relevant studies which primarily centered on stem cell utilization in explaining pathogenesis, gene expression, drug screening, and transplantation studies. 
Inclusion criteria:

1)The studies involving subjects of autism, Asperger and pervasive developmental disorder not otherwise specified (PDD-NOS); 2) studies published in peer-reviewed journals ; 3) in English and studies involving human preferably but combined studies of human and animals also included.

Exclusion criteria:

1) If they did not mention the collection(s) in the research data, references, acknowledgments or supplementary materials; 2) If studies only concerned animal models of ASD without using/application on ASD human individuals; 3) articles not published in peer-reviewed journals; 4) studies in languages other than English.

For each article, the study material was analyzed for: a) publication status of article, (b) the article subject, (e.g. essential properties of stem cells, conceivable sources, gene expression, pattern of differentiation, immune-modulatory impacts, safety issues, routes of administration, components of pathogenesis supporting modification in neural structure, genetic variations, immune-hyperactivity state, hypoperfusion of brain, oxidative stress, inflammatory and natural environmental factors) as well as interventions with respect to drug screening and transplantation treatment completely different setting, (c) application aspects (any constraints such as journal lists, conditions, or specialties). The framework for data gathering included looking of all study references to find some other related articles not caught within the preliminary evaluation. Duplicate studies were erased utilizing advanced object identifiers and manually comparing titles, writers, production dates, and article metadata. Every single article was screened separately by two investigators for analysis, and contradiction was settled through discussion.

\section{RESULTS}

We directed this review that reveals the utilization of stem cells in deciding the ASD pathogenesis, genetic contribution and restorative mediations alongside fundamental properties, distinctive sources, and method of administration of stem cells. Articles identified with ASD and stem cells were gathered through PubMed chiefly, different sources incorporate MEDLINE, 
Journal of Neural Transmission, Oxford Journal, Psych Central, PsycINFO, Cochrane library, and different daily papers.

Keywords were chosen and searched for relevant research articles as "stem cell therapy and autism" gave 139 studies; "stem cell therapy and autistic spectrum disorder" gave 92 studies; "stem cells and autistic spectrum disorder" gave 240 studies; "stem cells and autism" gave 438 studies; "induced pluripotent stem cells and autistic spectrum disorder" gave 108 studies; "induced pluripotent stem cells and autism" gave 154 studies; hence, total of 1171 appeared. In the wake of dealing with duplicates $=212$, left us with 959 studies. Free full-text studies were 720 in number. A set of 387 studies remained after screening titles and abstracts, and of these, 55 studies were included in the review.
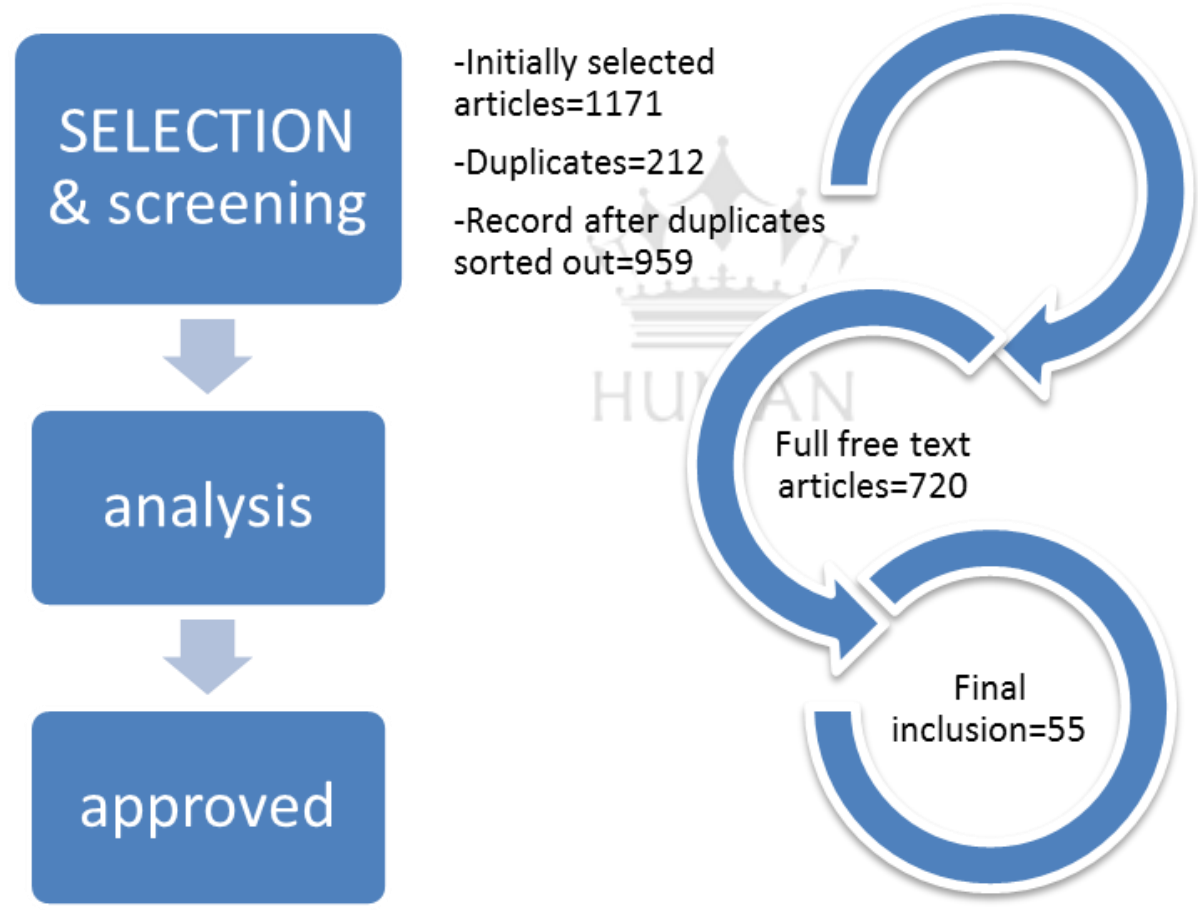

No study was incorporated into last round simply screening the abstract. The reviews with a high possibility of bias and those with obscured or blended information were avoided. Any studies published in non-popular journals were additionally barred in order to keep up the high standards of the study. A few investigations were rejected because they did not gauge interfaces between undifferentiated stem cells and autistic spectrum disorder directly. 
Data contains a sum of 4090 individuals among them 155 were children,2886 were in control group,3913 adults were used in genetic manifestation studies,25 children were utilized in medicate screening trial and 130 children alongside with ten adults were utilized in stem cell transplantation studies. The animals incorporated in the studies were rodents especially the mouse. Among genetic assessment studies, 1041 ASD individuals were found to nonsynonymous mutations of TRCP6 gene when contrasted with 2878 controls ${ }^{16}$. Chromodomain helicase DNA-binding protein 8 (CHD8) were recognized in 12 people portraying altered expression of 1715 genes, including both protein-coding and noncoding ASD and zero controls, representing an exceedingly noteworthy association ${ }^{11}$. Administration of pioglitazone (PPARgamma agonist) in 25 children came about $75 \%$ improvement in response on aberrant behavior checklist $^{17}$. Infusing human neural progenitor cells (hNPCs) in a group of twenty-two children with pervasive developmental disorder, including 13 children with Rett syndrome and 9 children with autism, indicates 17 patients, including 8 patients with autism and 9 patients with Rett syndrome, variable improvement. Total scores on Autism Behavior Checklist and social communication and language scores were likewise radically lessened 1 year after transplantation $(\mathrm{P}<0.05)^{18}$. Study of 71 children with incurable neurological disorder includes administration of bone marrow-derived mononuclear cells, $88 \%$ of cases showed a variable level of improvement ${ }^{19}$.

Another study involving 37 subjects diagnosed with autism with the formation of three groups: 1) combined transplantation of human cord blood mononuclear cells CBMNC group (14 subjects, received CBMNC transplantation and rehabilitation therapy); 2) Combination group (9 subjects, received both CBMNC and umbilical cord-derived mesenchymal stem cells (UCMSCs) transplantation and rehabilitation therapy); 3) Control group (14 subjects, received only rehabilitation therapy). They were accessed utilizing the Childhood Autism Rating Scale (CARS), Clinical Global Impression (CGI) scale and Aberrant Behavior Checklist (ABC). Transplantation of CBMNCs indicated efficacy contrasted with the control group; notwithstanding, the blend of CBMNCs and UCMSCs delineated more significant restorative impacts than the CBMNC transplantation alone ${ }^{20}$. 


\section{DISCUSSION}

Definition of MSC:

Concurring to the International Society of Cellular Therapy, MSCs are characterized by the following minimal set of criteria: (1) competent of developing in adherence to plastic surface of dishes under standard culture conditions; (2) show cyto specific cell surface markers, i.e. CD105, CD90, and CD73, to be negative for other cell surface markers, i.e. CD45, CD34, CD14, and $\mathrm{CD} 11 \mathrm{~b}$; (3 have the capacity to distinguish into mesenchymal lineages, under appropriate in vitro conditions $^{21}$. Stem cells are nonhematopoietic (of mesodermal in origin) having a multilineage potential, as they are capable of differentiating into both mesenchymal and non mesenchymal lineages, primarily found in the bone marrow of adults, giving rise to skeletal muscle cells, blood, fat, vascular, and urogenital systems, and to connective tissues throughout the body.

Source of stem cells

\section{Embryonic stem cells}

Origin of embryonic stem cells (ESCs) takes place from early stages of embryonic development ${ }^{22,23}$, fit for differentiating into hematopoietic cell lineages, offering to ascend to all blood cell types and subtypes of the immune system (i.e. T cells, NK cells, and dendritic cells $)^{24,25}$. Rejection is shown in cases by recipient immune system when HLA-II expression occurred $^{26}$. Paracrine activity is observed at the embryonic stage of their development ${ }^{27}$.

\section{Fetal stem cells (FSCs)}

Fetal mesenchymal stem cells apply immunomodulatory impacts ${ }^{28}$ and show less degree of senescence. In contrast to ESCs, they are incapable of converting into teratomas posttransplantation ${ }^{29}$ and have a better capacity to differentiate into pluripotency than neonatal and adult cells ${ }^{30}$. Rather than MSCs, in early stages FSCs demonstrate pluripotency stem cell markers Nanog, Oct-4, SSEA-3, SSEA-4, Tra-1-60, and Tra-1-81, Rex-1 while mesenchymal stem cell markers, that is, CD73, CD90, and CD105 are showed up after some time, though unequipped for expressing hematopoietic or endothelial markers (i.e., CD14, CD34, and 
CD45) ${ }^{31}$. FSCs obtained from first-trimester human fetuses are able of survival, show a mature neuronal phenotype and becoming functional after transplantation ${ }^{32}$. FSCs apply paracrine trophic activities on host tissues (predominantly, immune, brain and gastrointestinal tissues) and can form several diffusible neurotrophic and growth factors.

\section{Adult stem cells}

They are mesodermal in origin, derived from the bone marrow of children and adults capable of self-regeneration and transformation into fat, cartilage, and stromal cells of the bone marrow ${ }^{33,34}$. The different sources for obtaining the stem cells incorporate fibroblasts ${ }^{35,36}$; somatic cells ${ }^{37,38}$; the peripheral blood mononuclear cells (PBMCs) ${ }^{39}$. Somatic cells provide the source for iPSC, for example, pancreatic beta-cells, $\operatorname{liver}^{40}$, and keratinocytes ${ }^{41}$. However, in some cases, terminally differentiated cells, such as B-cell lymphocytes ${ }^{42}$ and neurons ${ }^{43}$ have also been utilized.

\section{Adipose-derived MSCs}

Adipose-derived mesenchymal stem cells (AD-MSCs) are getting popular regarding autologous cell therapy, capable of differentiating into mesenchymal lineage including adipogenic, osteogenic, chondrogenic variants. They can be obtained by methods like small volume lipoaspirate $^{44}$.

\section{Umbilical cord-derived MSCs}

Among different sources of stem cells include both umbilical line and placenta ${ }^{45}$. Umbilical cord blood-derived mesenchymal stem cells are hematopoietic. The stroma of the cord is also a source of primitive stem cells dwelling in the Wharton's jelly (WJCs). WJCs delineate low levels of human leukocyte antigen (HLA)- $\mathrm{ABC}$ and no HLA-DR so ready to limiting the mouse splenocytes and human fringe blood lymphocytes ${ }^{46}$. WJCs act as trophic support to neighboring cell populations and conjointly hold immunomodulation properties ${ }^{47}$. Moreover, human cord blood mononuclear cells (CBMNCs) have also been transplanted successfully ${ }^{20}$. 
Neural stem cells (NSCs)

Neural stem cells (NSCs) or neuroprogenitor cells (NPCs) are self-regenerating potential and differentiate into numerous cell types of central nervous system, can be gotten from both fetal and adult stem cells ${ }^{48}$. They can be inferred from viable human neurons and glial cells ${ }^{49}$; dental pulp cells ${ }^{16}$; from adult stem cells located in the lamina propria of olfactory epithelium hence named olfactory ecto-mesenchymal stem cells $(\mathrm{OE}-\mathrm{MSC})^{50}$;

Properties of stem cells:

\section{Genes expression}

The change of one cell type to another is called Transdifferentiation whereas the process of reprogramming a cell type into a pluripotent state and then into the cell type of interest is called reprogramming ${ }^{51}$. The first impacting genes deciding the identity and coordinating the reprogramming of mouse embryonic fibroblasts into iPSCs incorporate Oct3/4, Sox2, Klf4, and c-Myc ${ }^{52,53}$. The resulting generation of mouse embryonic stem cells was indistinguishable to parent cells and showing pluripotent stem cell markers, SSEA-3, SSEA-4, Tra-1-60, and Tra-181. The association of comparable genes was also portrayed in human adult dermal fibroblasts to iPSC $^{52}$. In another data, a slight distinctive factors Oct4, Sox2, Nanog and Lin28 were utilized in human fibroblast reprogramming ${ }^{54}$.

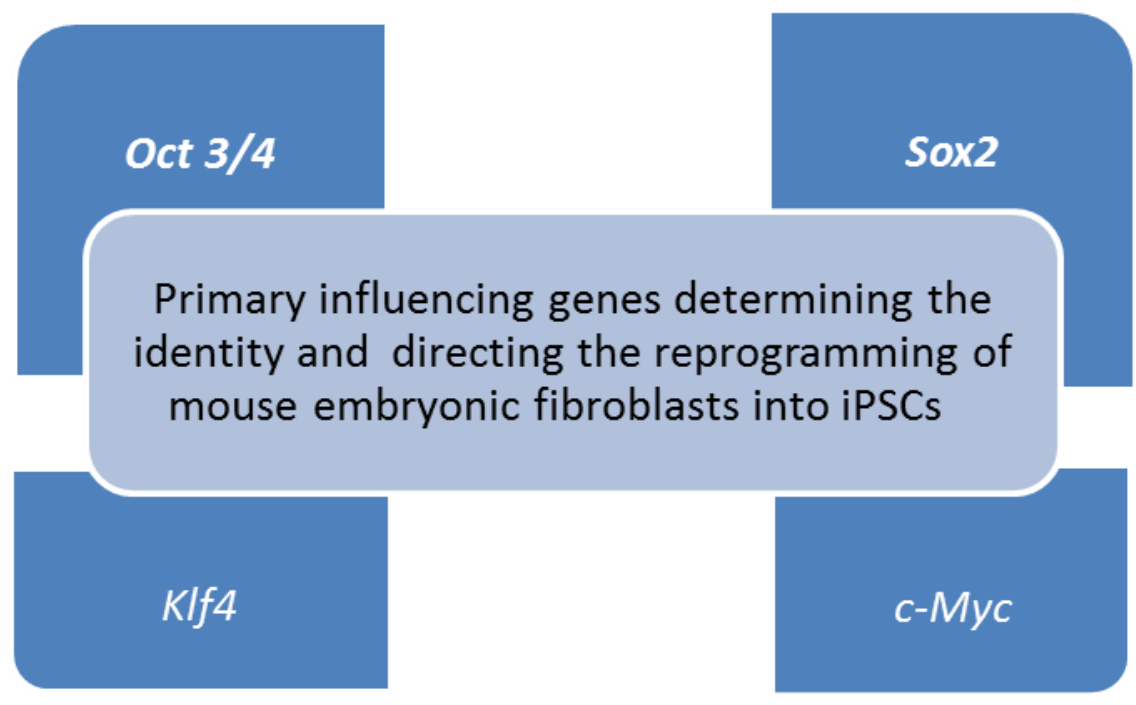


Several studies revealed transdifferentiation of human fibroblast into neurons ${ }^{55,56}$. Vierbuchen et al., inspired by the work of Yamanaka and Melton's groups, came up with 19 genes which were important in neural development or epigenetic modifications. These incorporate Brn2 (Pou3f2), Ascl1 and Myt11 transcription factors, determine the destiny of mouse embryonic stem cells and postnatal mouse fibroblasts into neurons ${ }^{57}$. Human dermal fibroblasts could also be transdifferentiated into neurons by the impact of NeuroD1, a basic helix-loop-helix transcription factor in about 3 weeks.

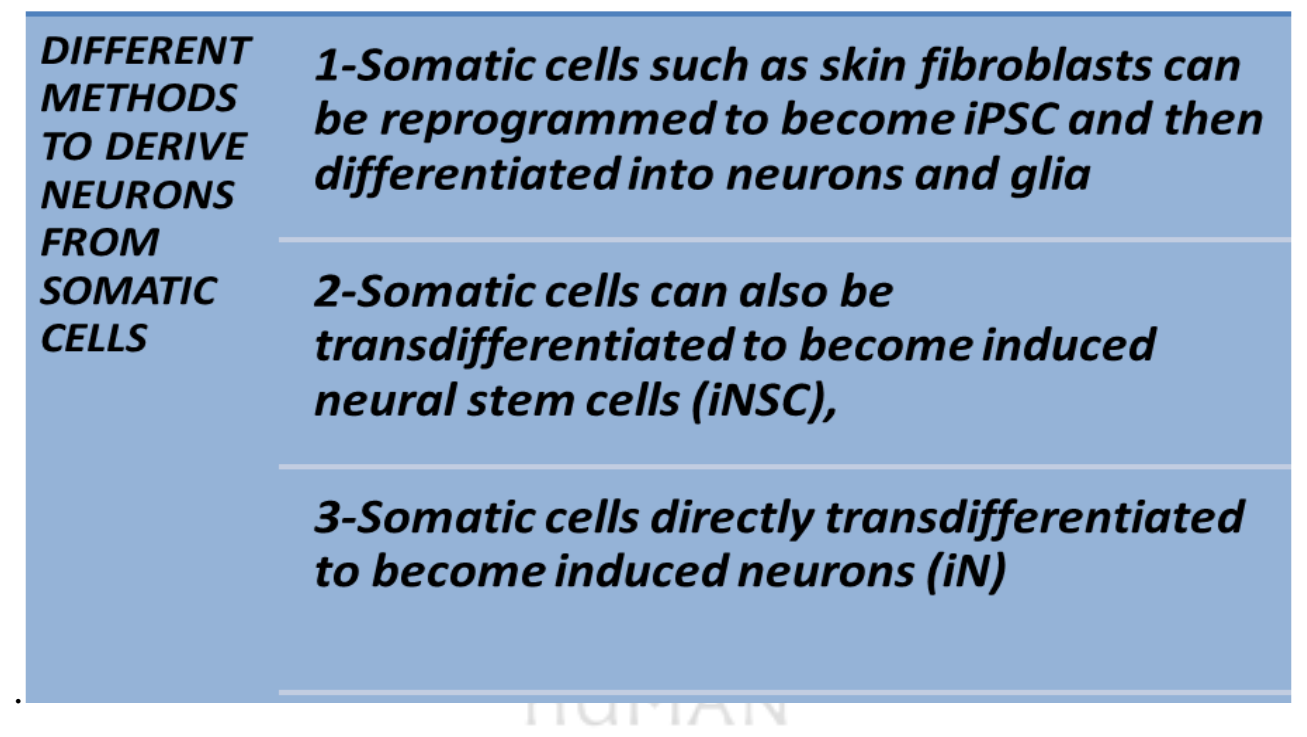

Transdifferentiation of fibroblasts straightforwardly into neural stem cells (NSC) includes several transcription factors ${ }^{58-62}$. It was illustrated that fibroblasts could turn into NSCs by regulating Sox 2 alone and also delineated the effect of Oct4, Sox2, Klf4, and c-Myc ${ }^{59}$.

\section{Differentiation pattern and guidance:}

Stem cells can generate a three-dimensional structure of an organ i.e., laminar structure of the brain that model the developmental staging. Pluripotent stem cells, when permitted to develop in culture, will shape neurospheres in a three-dimensional design mirroring the layers of the cortex. Migration of $\mathrm{N}$-cadherin+ neural progenitors towards Sox 1+ outer regions and afterward these cells slowly move inward. On cut section, immunofluorescent staining uncovers Reelin+ and Tbr1+/Reelin-/Bf1+ neurons on days 7 and 8, whereas Ctip2+/ Emx1+ neurons were shown on and after day 10. Brn2+/Bf1+ cells were present during days 10-13. These Brn2+ neurons 
moreover appear with other upper CP markers such as Cux1 and Satb2 ${ }^{63}$. Moreover, birth-date examination pulsing, BrdU during days 8-14 and analyzing the BrdU positive cells on day 16. The birth of Reelin+ (layer I), Tbr1+/Bf1+ (layer VI), Ctip2+ /Emx1+ (layer V), and Brn2+/Tuj1+ (layer II/III) neurons were present on days 8-10, 9 to 10,10 to 11 , and 12 to 13 , respectively.

Embryonic stem cells (mESC) produce NSCs which pass through the normal stages of developmental and differentiate into neurons ${ }^{64}$. By uncovering $\mathrm{mESC}$ with a sonic hedgehog inhibitor, cyclopamine, progenitors gets differentiated to the dorsal cortical. On advance analyzing these pyramidal cells, markers of lower layer neurons appeared over time. Studying axonal projections of grafted ESC derived neurons by TAU (MAPT)-GFP knock-in ESC line, Gaspard et al. , after growing the TAU-GFP mESC for 12-17 days, the differentiated cells were transplanted into the frontal cortex of neonatal mice, showing the neurons exhibit axons which followed cortical efferents, uncovers that the neurons imitate cortical layer.

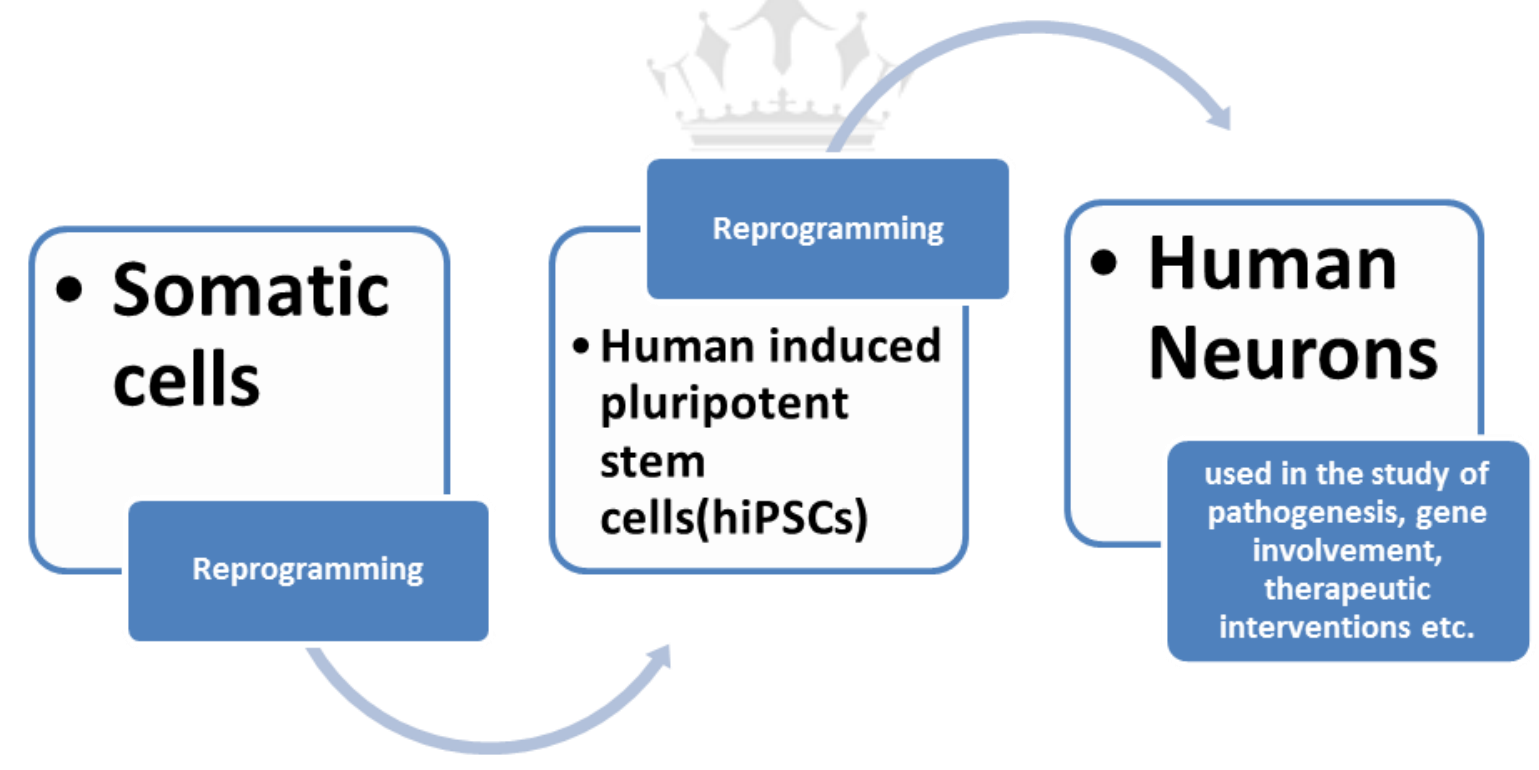

Immune-modulatory effects:

MSCs have shown the capacity to inhibit the immune system and enhance neurogenesis, in this way their application in therapeutics revealed likely outcomes in different settings including some clinical studies even ${ }^{65}$. This is due to the unique ability of MSCs i.e., migration to injury 
location and release of pro-inflammatory cytokines, subsequently smothering immune system and making themselves a successful transplantation modality in autologous as well as heterologous setting without requiring immunosuppressant drugs ${ }^{66-69}$. For this reason, genetic modification or pretreatment before transplantation is not recommended ${ }^{70,71}$.

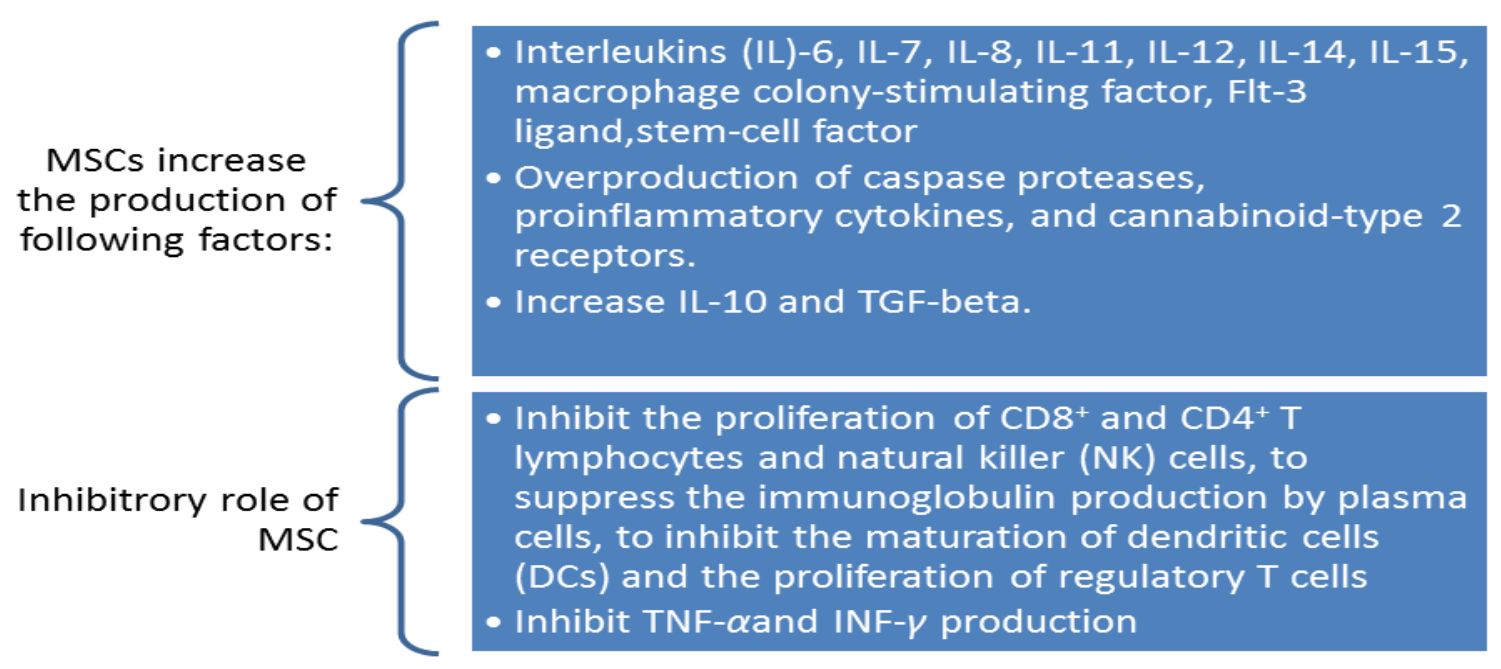

The paracrine functions of stem cells (i.e., the bio-pharmacy or the secretome) are picking up huge reputation ${ }^{72,73}$. Implanted stem cells utilize diverse mechanisms to cause their immunomodulatory effect including 1) cell-to-cell contact activation mechanism through which pro-inflammatory macrophages are changed into anti-inflammatory macrophages ${ }^{74,75}$; 2) paracrine secretome activity ${ }^{76}$. MSCs exert the plastic response in the host damaged tissue, synthesize and release survival-promoting growth factors as well as the synaptic transmitter by causing local re-innervation, integrate into existing neural and synaptic network, and establishing plasticity $^{77}$.

Variations in levels of TNF- $\alpha$ and INF- $\gamma$ (decrease)and IL-10 (increase) levels inhibit T-cell recognition and expansion ${ }^{78}$. MSCs also able to change the NK cells through paracrine activity by producing PGE-2 and IL-10 which expert impact by changing T-cells responses ${ }^{79}$, besides, by expressing tryptophan catabolizing enzyme indoleamine 2,3,-dioxygenase as well as Galectin$1^{80,81}$. MSCs also regulate immune response by the release of secrete immune inhibitory factors such as IL-10 and TGF-b without modifying the process of antigen presentation to T cells ${ }^{82,83}$. 
It is not the culture time of MSCs to permit them picking up immunosuppressive capability and accomplishing the functional maturation to initiate allogeneic $\mathrm{T}$ cell apoptosis, when compared to freshly isolated, irradiated MSCs ${ }^{84}$.

\section{Safety:}

Administration of 1-2.2 × 106 cells/kg of MSCs have caused no adverse effects while considering bone marrow cell transplantation ${ }^{85}$. Although further studies can uncover the real destiny concerning the safety of engrafting stem cells.

\section{.Route of delivery:}

Stem cells can be transplanted through various routes including injection into the lateral ventricle 86; intramuscular approach ${ }^{19}$; intranasal administration ${ }^{19}$; intrathecal approach ${ }^{19}$; intravenous $\operatorname{administration}^{20}$.

\section{Pathogenesis (Possible mechanisms of ASD):}

\section{Alteration in neuronal structure:}

Astroglial cells, or astrocytes, encompass different parts of the cerebral endothelium and assume an essential job in directing perfusion ${ }^{88}$ and blood-brain barrier function ${ }^{89}$. Neurons derived from iPSCs of the unhealthy patient indicated a diminished number of neural connections and reduction in soma size, altered density of spine and electrophysiological absconds involving calcium signaling ${ }^{35}$. Synaptic deficits in ASD are directed by genes controlling protein synthesis, receptor development, and post-synaptic scaffold architecture design ${ }^{90}$.

Astrocyte dysregulation (i.e., neuronal development inconsistency, variety in size and number of microglia) is associated with the pathophysiology of $\mathrm{ASD}^{65,91}$. Indeed, ASD subjects demonstrate a diminished number of Purkinje cells in the cerebellum ${ }^{92}$. These changes could reflect deficient cortical organization in ASDs development. Furthermore, autism is related to dysregulation in the development and plasticity of dendritic spine morphology ${ }^{93}$. In autism, 
excitatory and inhibitory cortical neurons add to minicolumn structure abnormalities and functional imbalance in cortex ${ }^{48}$.

By synchronous and controlled formation of late cortical progenitors (LCPs) differentiating into glutamatergic cortical neurons of upper layers by iPSCs empower us to study the ability of LCPs in various periods of growth and associated molecular modifications included. The decline in time of differentiation of these progenitor cells into neurons provide a realistic chance to ponder on postmitotic neurons from these LCPs and response of various molecules affecting extension and branching of neurites ${ }^{94}$. The cellular level investigation of glutamatergic synapse arrangement, capacity, and maintenance by iPCSs modeling have empowered us to know the neuronal and synaptic development process in cells ${ }^{95}$.

Breaking down of GABAergic neurons and therefore inhibitory signals result in the inability to direct the neuronal circuit engaged with ASD. By utilizing combinatorial and transient tweak of developmentally relevant dorsoventral and rostrocaudal signaling pathways (SHH, Wnt, and FGF8), we proficiently produced medial ganglionic eminence (MGE) cells from iPSCs. Secretion of various molecules originated by adjacent sources and moving to target locales help to coordinate the differentiation of GABAergic interneuron progenitors emerging from (MGE) versus caudal ganglionic eminence (CGE) by FGF8/FGF19 signaling pathway.Lhx6- expressing GABAergic interneurons produce from human MGE cells. By tweaking the signs may help in the healthy growth of GABAergic interneurons ${ }^{96}$. Cortical GABAergic interneurons regulate cortical excitation, and their brokenness is embroiled in a multitude of neuropsychiatric disorders ${ }^{97}$.

\section{Genetic mutations:}

iPSCs give us a chance to uncover the conceivable role of genetic variations in the ASD patient and their products engaged with the arrangement of the unique feature of the human brain. It additionally settles the question of separation of undifferentiated stem cells into various pathways extending from general to particular ones and into various cells at influenced sites (e.g., neurons, cardiomyocytes, hepatocytes, and myocytes) ${ }^{38}$. Advancements of gene-editing innovations on iPSCs are empowering new methodologies for enlightening the pathogenic 
explanation of human diseases ${ }^{98}$. We can investigate distinctive disease markers and profile the diverse scope of gene expression ${ }^{99}$.

An examination report a de novo balanced translocation disturbance of TRPC6 (a cation channel), TRPC6 decrease or haploinsufficiency prompts changed neuronal improvement, morphology and working and impact of methyl $\mathrm{CpG}$ binding protein-2 (MeCP2) levels on TRPC6 articulation (transformations in MeCP2 uncovering normal pathways among RTT disorder) in a non-syndromic autistic person. Genetic sequencing of TRPC6 in 1041 ASD people and 2872 controls uncovered fundamentally more nonsynonymous changes in the ASD populace. Without further ado, that TRPC6 is a predisposing gene for ASD that may demonstrate in a multiple-hit model ${ }^{16}$.

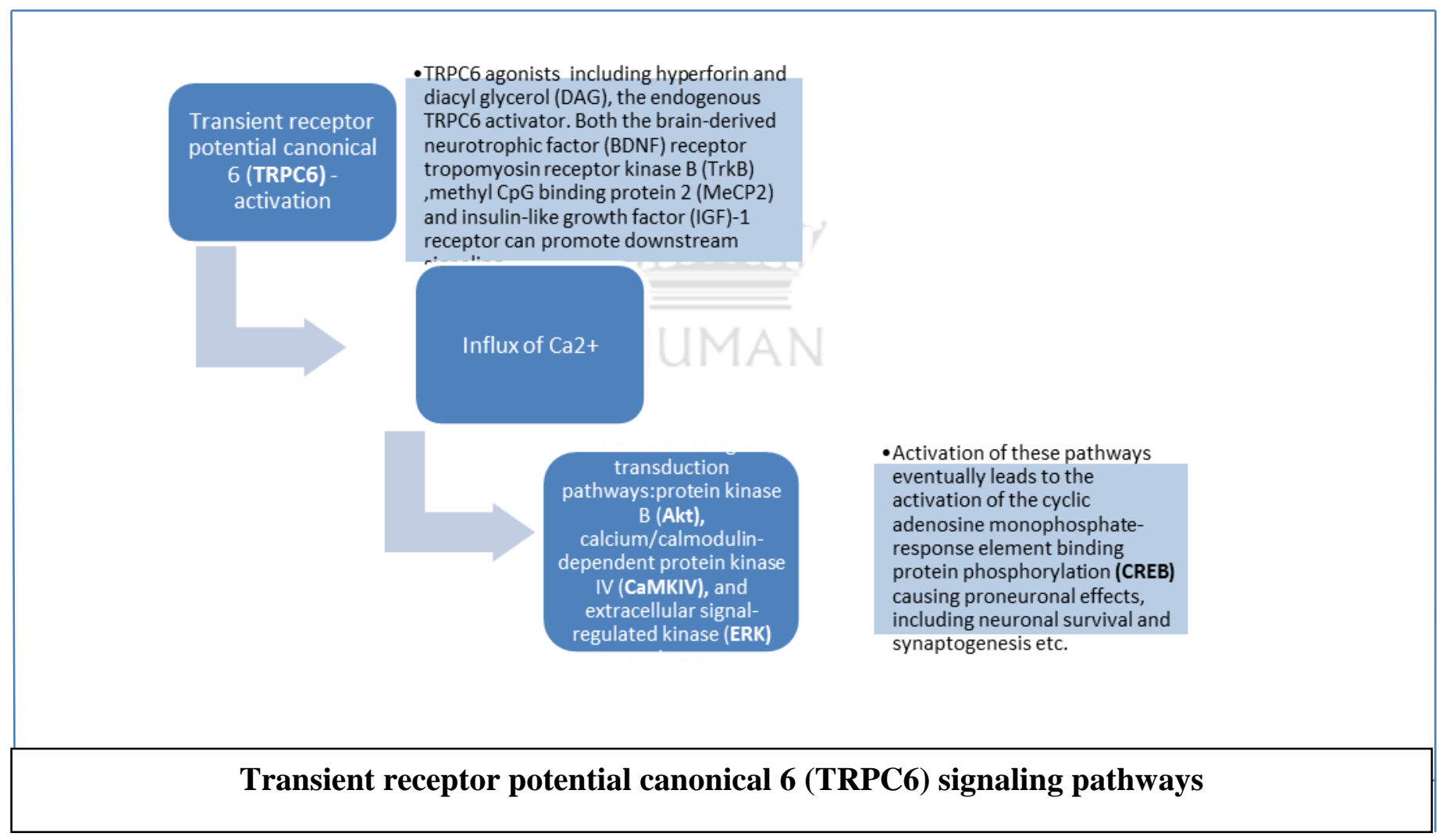

Chromodomain helicase DNA-binding protein 8 (CHD8) inadequacy assume an immediate impact in neuronal development and ASD hazard. (CHD8) which codes for an individual from the CHD group of ATP-dependent chromatin-remodeling factors. De novo loss-of-function mutations were recognized in 12 people with results in adjusted articulation of 1715 genes, 
including both protein-coding and noncoding ASD and zero controls. Little meddling RNAmediated knockdown of CHD8 in human neural progenitor cells taken after by RNA sequencing uncovered that CHD8 insufficiency RNAs. Among the 10 most changed transcripts, 4 (40\%) were noncoding RNAs. The transcriptional alterations among protein-coding gene included a very interconnected system of genes that are more influencing in neuronal growth and in beforehand recognized ASD competitor qualities ${ }^{11}$.

RNA-seq investigation did on iPSCs that were heterozygous for CHD8 knockout (KO) alleles created utilizing CRISPR-Cas9 gene editing.TCF4 quality articulation was, once more, altogether upregulated. Pathway investigation completed on differentially expressed genes (DEGs) uncovered an advancement of genes associated with neurogenesis, neuronal differentiation, forebrain growth, Wnt/ $\beta$-catenin signaling, and axonal guidance, like our past examination on NPCs and monolayer neurons. There was additionally huge cover in our CHD8+/ - DEGs with those found in a transcriptome investigation. Surprisingly, the best DEG in the analysis was the non-coding RNA DLX6-AS1, which was uniquely upregulated in both studies; DLX6-AS1 managed the expression of members of the DLX (distal-less homeobox) gene family and was likewise upregulated. DLX genes code for interpretation factors that assume a crucial job in GABAergic interneuron differentiation ${ }^{100}$.

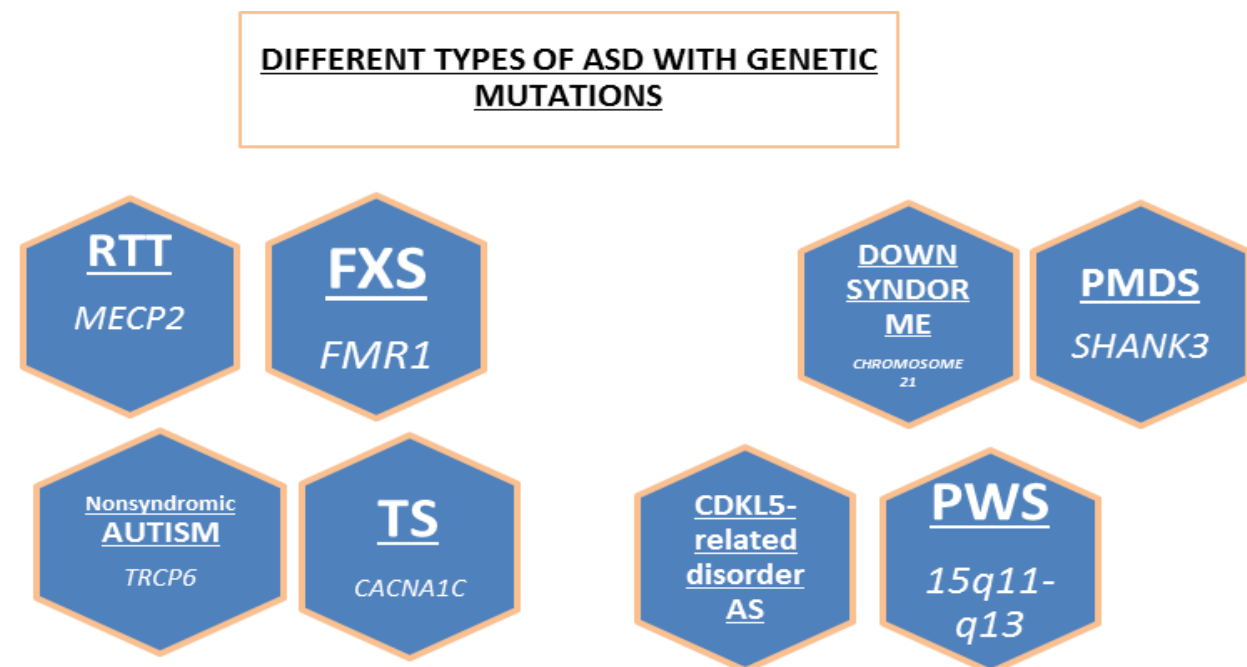

$\mathrm{ASD}=$ autism spectrum disorder; RTT=Rett syndrome; $\mathrm{FXS}=$ fragile $\mathrm{X}$ syndrome; PMDS=Phelan-McDermid syndrome; TS=Timothy syndrome; $C D K L 5=$ cyclin-dependent kinase-like $5 ; A S=$ Angelman syndrome; PWS=Prader-Willi syndrome; 
Interruption of a particular gene, GTDC1 utilizing long- insert DNA paired-end tag (DNA-PET) sequencing approach, in wild kind human neural progenitor cells (NPCs) and neurons portrayed a comparative phenotype as patient's iPSCs ${ }^{101}$; clustered regularly interspersed short palindromic repeat-associated protein 9 (CRISPR/Cas9) method for genome altering in 3D organoid frameworks has been utilized to analyze transformations that reason autism ${ }^{102}$ and in the disease modeling field ${ }^{103}$. In an alternate report, hESC were produced with the trinucleotide expansion recognized by preimplantation genetic diagnosis. The ESC showed FMR1, and the promoter was unmethylated. Notwithstanding, the FMR1 promoter gets methylated upon differentiation and causing a decrement of FMR1 protein ${ }^{104}$. Curiously, two other groups utilized somatic cells with the trinucleotide expansion to iPSC. Their finding suggested methylation of FMR1 promoter leading to an inhibitory effect on FMR1 expression ${ }^{15}$. The promoter of FMR1 becomes methylated due to the trinucleotide repeat and is resistant to the reprogramming process.

\section{Immune hyperactivity in autism:}

Astrocyte physiologically beat disease by producing inflammatory cytokines, for example, TNFalpha, IL-1beta, and IL-6 ${ }^{105}$ and also different chemokines, for example, CXCL10, CCL2, and BAFF regulate adaptive immunity ${ }^{106}$. Autism people indicate diminish levels of inflammatory cytokines, for example, IL-10 $0^{107}$ and TGF-beta ${ }^{108}$, subsequently building up a hyperactivity of immune state ${ }^{16}$. ELISA of CSF samples of ASD patients reveals overproduction of inflammatory cytokines $^{109}$. Plasma level of INF-gamma is additionally discovered brought up in ASD people 106. T cells and B cells anomalies have likewise been found in the autism individuals comprising of systemic $\mathrm{T}$ cell lymphopenia, altered cytokines formation and variable reactions to mitogens ${ }^{110}$. Studies have indicated a change in regulation of the immune system mainly CD3+, CD4+, and CD8+ T cells, and additionally in NK cells in ASD patients. The excess generation of IL-1 $\beta$ by peripheral blood mononuclear cells (PBMCs) have also been reported ${ }^{111}$.

In autism individual, a few kinds of autoantibodies have discovered clarifying the immune system nature of illness when contrasted with controls, including antibodies to myelin essential protein, brain extracts ${ }^{112,113}$, Purkinje cells and gliadin extracted peptides ${ }^{114}$, neuron-axon filament, glial fibrillary acidic protein, and neutrophic factors ${ }^{115}$. Another viewpoint incorporates the high pervasiveness of immune system ailments in relatives of autism individuals ${ }^{116}$. 
Autoimmunity is related with both HLA haplotypes and also complement component gene polymorphisms ${ }^{117}$.

\section{Hypoperfusion of brain in autism:}

Youngsters with autism have been reliably appeared to have distorted, or subnormal CNS blood flows and also coming about hypoxia. Deformities incorporate basal hypoperfusion and diminished perfusion in response to stimuli that under typical conditions upregulates perfusion. In autism, the related hypoxia is not overwhelmingly apoptotic or necrotic to neurons however connected with malfunctioning ${ }^{118}$. Hypoperfusion may add to abandons by causing hypoxia as well as taking into consideration anomalous metabolite or neurotransmitter aggregation. This is one reason why glutamate toxicity has been embroiled in autism ${ }^{119}$ and a clinical trial at turning around this utilizing the inhibitor of glutamate toxicity, Riluzole, is as of now in advance. Different causes incorporate the oxidative stress and inflammatory processes and impact of ecological factors, therefore, helping the utilization of pharmaceuticals and stem cells as a conceivable contender for the treatment of $(\mathrm{ASD})^{120}$.

\section{THERAPEUTICS:}

\section{Drug screening}

iPSCs give great chance to get to the human neurons(late cortical progenitors /LCPs and cortical neurons of the upper layers), and astrocytes ${ }^{9,94}$, the headway in understanding the example of fundamental cell processes, genetic variability coding the neural tissue development has advanced the field of designing useful pharmacological and remedial interventions ${ }^{37}$. This includes the capacity to frame humanized illness display for the use of novel biogenic compounds influencing the ailment phenotype, focusing on the genetic changes and building up various cell substitution strategies ${ }^{36}$. A noticeable change appeared in the phenotypes of ASD people by use of insulin-like development factor-1 or TRPC6-particular agonist (hyperforin) and TRPC6 complementation ${ }^{16,121}$.

Investigation of basic functional units, i.e. synapses through iPSCs inferred framework uncovers the procedure of arrangement and working of glutamatergic synapses and deciding the illness 
pathologies for the better understanding of shared processes and revelation of conceivable interventions. The impact of IL-6 on mental health and social changes contemplated on iPSCs human cell-based models unveil the pathogenesis of maternal immune activation (MIA) and role of luteolin-a natural flavonoid found in eatable plants-could avoid MIA-mediated abnormalities. The neural tissue from human induced pluripotent stem cells (hiPSCs) got from embryoid bodylike aggregates were presented to IL-6 $(100 \mathrm{ng} / \mathrm{ml})$ for $24 \mathrm{~h}$ at day 51 .IL-6 exposures caused the structural changes, i.e. expanded the area ratio of astrocytes (GFAP-positive area ratio) and diminished the area ratio of early-conceived neurons (TBR1-positive or CTIP2-positive region proportion) and additionally hoisted levels of phosphorylated STAT3, these progressions can be counteracted by Luteolin ${ }^{122}$.

Trails on different medications are under scrutiny with variable outcomes. Usage of pioglitazone (PPAR-gamma agonist) in 25 youngsters came about $75 \%$ change accordingly on aberrant behavior checklist ${ }^{17}$. Psycho-stimulants, alpha-2 agonists, beta blockers, lithium, anticonvulsants, selective serotonin reuptake inhibitors, atypical antipsychotics, antidepressants, and mood stabilizers, are medications generally endorsed for significant help in ASD people, however, can't give cure ${ }^{6,7}$. Catatonia is treated with lorazepam and electroconvulsive therapy ${ }^{8}$.

Stem cell transplantation

MSC can tweak a hyperactive immune system and elevate neurogenesis to make therapeutic potentials ${ }^{65}$. The expansion of CRISPR/Cas9 genome altering gives incredible potential to customized cell replacement treatment with hereditarily redressed hiPSCs ${ }^{123}$.

Twenty-two kids with the pervasive developmental disorder were infused with human neural progenitor cells (hNPCs) into lateral ventricle, incorporating 13 youngsters with Rett disorder and 9 kids with autism; 17 patients, incorporating 8 patients with autism and 9 patients with Rett disorder, variable improvement. Autism Behavior Checklist before the operation, at one and six months post operation and after one year uncovered social communication scores were altogether diminished at a half year after transplantation and aggregate scores and communication and language scores were likewise radically lessened 1 year after transplantation $(\mathrm{P}<0.05){ }^{18} .71$ youngsters with a serious neurological issue, (for example, autism, Rett Syndrome, giant axonal 
neuropathy) were directed intrathecally and intramuscularly infusion of bone marrow-determined mononuclear cells. $88 \%$ cases indicated a variable level of improvement ${ }^{19}$.

In an alternate analysis, subjects were assessed prior and then afterward (6 and 12 months) organization of intravenously and subcutaneously fetal stem cells. The Autism Treatment Evaluation Checklist (ATEC) test and Aberrant Behavior Checklist (ABC) scores demonstrate noteworthy contrasts $(\mathrm{p}<0.05)$ for the spaces of social interaction, sensory, and generally speaking wellbeing, and decreases in the aggregate scores when contrasted with pretreatment values $^{124}$. Diverse information from the small pilot study including ten patients, who were taken after 3, 6, 12 or 24 months after the organization of stem cells. They were gotten to utilizing ISAA and WeeFIM scales indicating notable improvement ${ }^{2}$.

Another investigation including 37 subjects determined to have an autism with arrangement of three groups: 1) combined transplantation of human cord blood mononuclear cells /CBMNC group (14 subjects, got CBMNC transplantation and restoration therapy); 2) Combination group (9 subjects, got both CBMNC and umbilical cord-derived mesenchymal stem cells (UCMSCs) transplantation and recovery treatment), and 3) Control group (14 subjects, got just recovery treatment). They were administered weekly stem cells intravenously and intrathecally. They were gotten to utilizing the Childhood Autism Rating Scale (CARS), Clinical Global Impression (CGI) scale and Aberrant Behavior Checklist (ABC) when treatment indicating unusual distinction 24 weeks post-treatment. Transplantation of CBMNCs indicated adequacy contrasted with the control group; be that as it may, the mix of CBMNCs and UCMSCs delineated more significant remedial impacts than the CBMNC transplantation alone ${ }^{20}$. In another setting, an experiment about utilizing a mixture of MSC and cord blood CD34+cells has demonstrated an enhanced response in autistic kids ${ }^{125}$.

iPSCs transplantation can be made more profitable by setting up various assays with demonstrated efficacy to psychiatric disease pathophysiology, capably making and supporting specific neural cell types concerning provincial character is concerned, data reproducibility across over labs. Moreover, different proposals can be useful, including :(a) empowering the replication of results by systematizing conventions and tests used transversely over laboratories;(b) upgrading development by creating more affordable/speedier concentrating on 
techniques, scientists and measures; and (c) improving resource sharing and participation, with a highlight on brisk sharing of new cell lines, advances, and best practices, possibly melded into an open private organization ${ }^{126}$.

\section{Ethical issues:}

When, the more understandings regarding the job of iPSCs in ASD, the more discussions in autism research have been raised with the advancement of autism-specific iPSC biobanks demonstrate a real necessity for authorities to doubtlessly pass on the confinements and potential results of iPSC research to ensure the research participants can give informed and valid consent $^{127}$. Data about these studies vary in quality, making unusual conditions for parent's fundamental choice for a child's care. Moreover jumbling this scene are centers that promote these intercessions as an honest to goodness treatment for a cost. The general population who considered taking their child with ASD abroad for iPSCs transplantation on the premise of their usage of different wellsprings of stem cell-related health data information and their level of trust in these sources. Members uncovered that while the Internet was their most endless wellspring of information, it was not all around trusted. Alternatively, on the other hand, possibly, information sources trusted in most were examiners and the science journals in which they convey diverse guardians of children with ASD, and therapeutic administrations providers. These disclosures include a division between information searching for tendencies and information trusted in sources. A definitive helpfulness by utilizing iPSCs require more endeavors to build up the ultimate results in this field ${ }^{128}$.

\section{CONCLUSION}

iPSCs are equipped for producing pluripotent cells that can separate the assortment of related cell types; this property is the premise of their use in the field of research for the diseases that can't be contemplated legitimately on alive subjects due to the constrained accessibility of source and modified explanations of results. By giving in vivo disease models to the investigation of such complex disorders including ASD, give a chance to better understanding the conceivable component of pathogenesis, hereditary impacts and testing remedial methodologies. Here, we depicted the role of these iPSCs was very promising by uncovering the hidden aspects of 
pathogenesis, i.e. changes in neural structure, genetic transformations, molecular variability, immune hyperactivity state, hypoperfusion of brain, oxidative pressure, environmental and natural variables. Remedial intercessions concerning drug screening and transplantation treatment in the various setting are likewise being tried comprehensively, to acquire practical advances in this field. By the iPSCs use in ASD, a promising future can be predicted. However, the rest of choice can be left on future analysts for advancing investigation in the field of research.

Disclosure Statement:

There is no conflict of interest in term of financial support or relationship.

Figure Legend:

All the figures has been pasted to the specific place in the article along with separate file (jgp.) and no description is needed separately.

\section{Excess of Word Count}

This review article have almost 5500 words excluding title page and references.

Author Contributions:

All authors who have contributed equally as a group to each of the key contributions i.e. conception and design of the study; acquisition and analysis of data; drafting the manuscript or figures: or others.

\section{REFERENCES}

1. Association AP. Diagnostic and Statistical Manual of Mental Disorders. 5. Arlington: American Psychiatric Publishing; 2013.

2. Bansal H, Verma P, Agrawal A, Leon J, Sundell IB, Koka PS. A Short Study Report on Bone Marrow Aspirate Concentrate Cell Therapy in Ten South Asian Indian Patients with Autism. J Stem Cells. 11(1):25-36. http://www.ncbi.nlm.nih.gov/pubmed/28296862. Accessed July 22, 2018.

3. Ardhanareeswaran K, Coppola G, Vaccarino F. The use of stem cells to study autism spectrum disorder. Yale $J$ Biol Med. 2015;88(1):5-16. http://www.ncbi.nlm.nih.gov/pubmed/25745370. Accessed July 22, 2018.

4. Reiersen AM, Todd RD. Co-occurrence of ADHD and autism spectrum disorders: phenomenology and 


\section{www.ijsrm.humanjournals.com}

treatment. Expert Rev Neurother. 2008;8(4):657-669. doi:10.1586/14737175.8.4.657

5. McCracken JT. Safety issues with drug therapies for autism spectrum disorders. J Clin Psychiatry. 2005;66 Suppl 10:32-37. http://www.ncbi.nlm.nih.gov/pubmed/16401148. Accessed September 5, 2018.

6. Tandon M, Pruett JR. J. An overview of the use of antidepressants in children and adolescents. Mo Med. 2008;105(1):79-85.

7. Nevels RM, Dehon EE, Alexander K, Gontkovsky ST. Psychopharmacology of aggression in children and adolescents with primary neuropsychiatric disorders: A review of current and potentially promising treatment options. Exp Clin Psychopharmacol. 2010;18(2):184-201. doi:10.1037/a0018059

8. Dhossche DM, Shah A, Wing L. Blueprints for the Assessment, Treatment, and Future Study of Catatonia in Autism Spectrum Disorders. In: International Review of Neurobiology. Vol 72. ; 2006:267-284. doi:10.1016/S00747742(05)72016-X

9. Yuan SH, Shaner M. Bioengineered stem cells in neural development and neurodegeneration research. Ageing Res Rev. 2013;12(3):739-748. doi:10.1016/j.arr.2013.04.002

10. Committee IAC. 2010 Autism spectrum disorder research portfolio analysis report. 2012. http://iacc.hhs.gov/portfolio-analysis/2010/index.shtml.

11. Haggarty SJ, Silva MC, Cross A, Brandon NJ, Perlis RH. Advancing drug discovery for neuropsychiatric disorders using patient-specific stem cell models. Mol Cell Neurosci. 2016;73:104-115. doi:10.1016/j.mcn.2016.01.011

12. Farra N, Zhang W-B, Pasceri P, Eubanks JH, Salter MW, Ellis J. Rett syndrome induced pluripotent stem cellderived neurons reveal novel neurophysiological alterations. Mol Psychiatry. 2012;17(12):1261-1271. doi:10.1038/mp.2011.180

13. Yazawa M, Hsueh B, Jia X, et al. Using induced pluripotent stem cells to investigate cardiac phenotypes in Timothy syndrome. Nature. 2011;471(7337):230-234. doi:10.1038/nature09855

14. Institute NHG. Learning about autism. http://www.genome.gov/25522099. Published 2012.

15. Urbach A, Bar-Nur O, Daley GQ, Benvenisty N. Differential Modeling of Fragile X Syndrome by Human Embryonic Stem Cells and Induced Pluripotent Stem Cells. Cell Stem Cell. 2010;6(5):407-411. doi:10.1016/j.stem.2010.04.005

16. Griesi-Oliveira K, Acab A, Gupta AR, et al. Modeling non-syndromic autism and the impact of TRPC6 disruption in human neurons. Mol Psychiatry. 2015;20(11):1350-1365. doi:10.1038/mp.2014.141

17. Boris M, Kaiser CC, Goldblatt A, et al. Effect of pioglitazone treatment on behavioral symptoms in autistic children. J Neuroinflammation. 2007;4(1):3. doi:10.1186/1742-2094-4-3

18. Liu W-P, Wang J, Qu S-Q, et al. [Transplantation of human neural precursor cells in the treatment of children with pervasive developmental disorder]. Zhongguo Dang Dai Er Ke Za Zhi. 2013;15(10):860-865. doi:10.7499/j.issn.1008-8830.2013.10.012

19. Sharma A, Gokulchandran N, Chopra G, et al. Administration of autologous bone marrow-derived mononuclear cells in children with incurable neurological disorders and injury is safe and improves their quality of life. Cell Transplant. 2012;21 Suppl 1(1_suppl):S79-90. doi:10.3727/096368912X633798

20. Lv Y-T, Zhang Y, Liu M, et al. Transplantation of human cord blood mononuclear cells and umbilical cordderived mesenchymal stem cells in autism. J Transl Med. 2013;11(1):196. doi:10.1186/1479-5876-11-196

21. Dominici M, Le Blanc K, Mueller I, et al. Minimal criteria for defining multipotent mesenchymal stromal cells. The International Society for Cellular Therapy position statement. Cytotherapy. 2006;8(4):315-317. doi:10.1080/14653240600855905

22. Yabut O, Bernstein HS. The promise of human embryonic stem cells in aging-associated diseases. Aging (Albany NY). 2011;3(5):494-508. doi:10.18632/aging.100328

23. Evans M. Discovering pluripotency: 30 years of mouse embryonic stem cells. Nat Rev Mol Cell Biol. 2011;12(10):680-686. doi:10.1038/nrm3190

24. Ng ES, Davis RP, Azzola L, Stanley EG, Elefanty AG. Forced aggregation of defined numbers of human embryonic stem cells into embryoid bodies fosters robust, reproducible hematopoietic differentiation. Blood. 2005;106(5):1601-1603. doi:10.1182/blood-2005-03-0987 


\section{www.ijsrm.humanjournals.com}

25. Nakamura Y, Hiroyama T, Miharada K, Kurita R. Red blood cell production from immortalized progenitor cell line. Int J Hematol. 2011;93(1):5-9. doi:10.1007/s12185-010-0742-2

26. Tang C, Weissman IL, Drukker M. Immunogenicity of in vitro maintained and matured populations: potential barriers to engraftment of human pluripotent stem cell derivatives. Methods Mol Biol. 2013;1029:17-31. doi:10.1007/978-1-62703-478-4_2

27. Jackson SA, Schiesser J, Stanley EG, Elefanty AG. Differentiating Embryonic Stem Cells Pass through 'Temporal Windows' That Mark Responsiveness to Exogenous and Paracrine Mesendoderm Inducing Signals. Huang S, ed. PLoS One. 2010;5(5):e10706. doi:10.1371/journal.pone.0010706

28. Chen P-M, Yen M-L, Liu K-J, Sytwu H-K, Yen B-L. Immunomodulatory properties of human adult and fetal multipotent mesenchymal stem cells. J Biomed Sci. 2011;18(1):49. doi:10.1186/1423-0127-18-49

29. Abdulrazzak H, Moschidou D, Jones G, Guillot P V. Biological characteristics of stem cells from foetal, cord blood and extraembryonic tissues. $J \quad R \quad$ Soc Interface. 2010;7 Suppl 6(Suppl 6):S689-706. doi:10.1098/rsif.2010.0347.focus

30. Galende E, Karakikes I, Edelmann L, et al. Amniotic fluid cells are more efficiently reprogrammed to pluripotency than adult cells. Cell Reprogram. 2010;12(2):117-125. doi:10.1089/cell.2009.0077

31. Guillot P V., Gotherstrom C, Chan J, Kurata H, Fisk NM. Human First-Trimester Fetal MSC Express Pluripotency Markers and Grow Faster and Have Longer Telomeres Than Adult MSC. Stem Cells. 2006;25(3):646654. doi:10.1634/stemcells.2006-0208

32. Piroth T, Pauly M-C, Schneider C, et al. Transplantation of Human Fetal Tissue for Neurodegenerative Diseases: Validation of a New Protocol for Microbiological Analysis and Bacterial Decontamination. Cell Transplant. 2014;23(8):995-1007. doi:10.3727/096368913X666449

33. Beyer Nardi N, da Silva Meirelles L. Mesenchymal stem cells: isolation, in vitro expansion and characterization. Handb Exp Pharmacol. 2006;(174):249-282. http://www.ncbi.nlm.nih.gov/pubmed/16370331. Accessed September 5, 2018.

34. Frenette PS, Pinho S, Lucas D, Scheiermann C. Mesenchymal Stem Cell: Keystone of the Hematopoietic Stem Cell Niche and a Stepping-Stone for Regenerative Medicine. Annu Rev Immunol. 2013;31(1):285-316. doi:10.1146/annurev-immunol-032712-095919

35. Marchetto MCNN, Carromeu C, Acab A, et al. A model for neural development and treatment of Rett syndrome using human induced pluripotent stem cells. Cell. 2010;143(4):527-539. doi:10.1016/j.cell.2010.10.016

36. Ming G-L, Brüstle O, Muotri A, Studer L, Wernig M, Christian KM. Cellular reprogramming: recent advances in modeling neurological diseases. J Neurosci. 2011;31(45):16070-16075. doi:10.1523/JNEUROSCI.4218-11.2011

37. Vaccarino FM, Urban AE, Stevens HE, et al. Annual Research Review: The promise of stem cell research for neuropsychiatric disorders. J Child Psychol Psychiatry. 2011;52(4):504-516. doi:10.1111/j.1469-7610.2010.02348.x 38. Vaccarino FM, Stevens HE, Kocabas A, et al. Induced pluripotent stem cells: a new tool to confront the challenge of neuropsychiatric disorders. Neuropharmacology. 2011;60(7-8):1355-1363. doi:10.1016/j.neuropharm.2011.02.021

39. Varga E, Nemes C, Bock I, et al. Establishment of an induced pluripotent stem cell (iPSC) line from a 9-year old male with autism spectrum disorder (ASD). Stem Cell Res. 2017;21:19-22. doi:10.1016/j.scr.2017.03.013

40. Aasen T, Raya A, Barrero MJ, et al. Efficient and rapid generation of induced pluripotent stem cells from human keratinocytes. Nat Biotechnol. 2008;26(11):1276-1284. doi:10.1038/nbt.1503

41. Aoi T, Yae K, Nakagawa M, et al. Generation of Pluripotent Stem Cells from Adult Mouse Liver and Stomach Cells. Science (80- ). 2008;321(5889):699-702. doi:10.1126/science.1154884

42. Hanna J, Markoulaki S, Schorderet P, et al. Direct reprogramming of terminally differentiated mature B lymphocytes to pluripotency. Cell. 2008;133(2):250-264. doi:10.1016/j.cell.2008.03.028

43. Kim J, Lengner CJ, Kirak O, et al. Reprogramming of Postnatal Neurons into Induced Pluripotent Stem Cells by Defined Factors. Stem Cells. 2011;29(6):992-1000. doi:10.1002/stem.641

44. Locke M, Feisst V, Dunbar PR. Concise Review: Human Adipose-Derived Stem Cells: Separating Promise from Clinical Need. Stem Cells. 2011;29(3):404-411. doi:10.1002/stem.593

45. Witkowska-Zimny M, Wrobel E. Perinatal sources of mesenchymal stem cells: Wharton's jelly, amnion and 


\section{www.ijsrm.humanjournals.com}

chorion. Cell Mol Biol Lett. 2011;16(3):493-514. doi:10.2478/s11658-011-0019-7

46. Zhou C, Yang B, Tian Y, et al. Immunomodulatory effect of human umbilical cord Wharton's jelly-derived mesenchymal stem cells on lymphocytes. Cell Immunol. 2011;272(1):33-38. doi:10.1016/j.cellimm.2011.09.010

47. Carvalho \# MM, Teixeira \# FG, Reis RL, Sousa N, Salgado AJ. Mesenchymal Stem Cells in the Umbilical Cord: Phenotypic Characteriza-Tion, Secretome and Applications in Central Nervous System Regenerative Medicine. Vol 6.; 2011. https://pdfs.semanticscholar.org/0a72/82207ad14e22b0605e7bf39c0b403c9c0ea8.pdf. Accessed September 6, 2018.

48. Stevens HE, Smith KM, Rash BG, Vaccarino FM. Neural stem cell regulation, fibroblast growth factors, and the developmental origins of neuropsychiatric disorders. Front Neurosci. 2010;4. doi:10.3389/fnins.2010.00059

49. Beltrão-Braga PCB, Muotri AR. Modeling autism spectrum disorders with human neurons. Brain Res. 2017;1656:49-54. doi:10.1016/j.brainres.2016.01.057

50. Girard SD, Devéze A, Nivet E, Gepner B, Roman FS, Féron F. Isolating nasal olfactory stem cells from rodents or humans. J Vis Exp. 2011;(54). doi:10.3791/2762

51. Slack JMW. Metaplasia and transdifferentiation: from pure biology to the clinic. Nat Rev Mol Cell Biol. 2007;8(5):369-378. doi:10.1038/nrm2146

52. Takahashi K, Tanabe K, Ohnuki M, et al. Induction of Pluripotent Stem Cells from Adult Human Fibroblasts by Defined Factors. Cell. 2007;131(5):861-872. doi:10.1016/j.cell.2007.11.019

53. Takahashi K, Yamanaka S. Induction of Pluripotent Stem Cells from Mouse Embryonic and Adult Fibroblast Cultures by Defined Factors. Cell. 2006;126(4):663-676. doi:10.1016/j.cell.2006.07.024

54. Yu J, Vodyanik MA, Smuga-Otto K, et al. Induced Pluripotent Stem Cell Lines Derived from Human Somatic Cells. Science (80- ). 2007;318(5858):1917-1920. doi:10.1126/science.1151526

55. Ambasudhan R, Talantova M, Coleman R, et al. Direct Reprogramming of Adult Human Fibroblasts to Functional Neurons under Defined Conditions. Cell Stem Cell. 2011;9(2):113-118. doi:10.1016/j.stem.2011.07.002

56. Pang ZP, Yang N, Vierbuchen T, et al. Induction of human neuronal cells by defined transcription factors. Nature. 2011;476(7359):220-223. doi:10.1038/nature10202

57. Vierbuchen T, Ostermeier A, Pang ZP, Kokubu Y, Südhof TC, Wernig M. Direct conversion of fibroblasts to functional neurons by defined factors. Nature. 2010;463(7284):1035-1041. doi:10.1038/nature08797

58. Han DW, Tapia N, Hermann A, et al. Direct Reprogramming of Fibroblasts into Neural Stem Cells by Defined Factors. Cell Stem Cell. 2012;10(4):465-472. doi:10.1016/j.stem.2012.02.021

59. Kim J, Efe JA, Zhu S, et al. Direct reprogramming of mouse fibroblasts to neural progenitors. Proc Natl Acad Sci. 2011;108(19):7838-7843. doi:10.1073/pnas.1103113108

60. Lujan E, Chanda S, Ahlenius H, Sudhof TC, Wernig M. Direct conversion of mouse fibroblasts to selfrenewing, tripotent neural precursor cells. Proc Natl Acad Sci. 2012;109(7):2527-2532. doi:10.1073/pnas.1121003109

61. Ring KL, Tong LM, Balestra ME, et al. Direct Reprogramming of Mouse and Human Fibroblasts into Multipotent Neural Stem Cells with a Single Factor. Cell Stem Cell. 2012;11(1):100-109. doi:10.1016/j.stem.2012.05.018

62. Thier M, Wörsdörfer P, Lakes YB, et al. Direct Conversion of Fibroblasts into Stably Expandable Neural Stem Cells. Cell Stem Cell. 2012;10(4):473-479. doi:10.1016/j.stem.2012.03.003

63. Eiraku M, Watanabe K, Matsuo-Takasaki M, et al. Self-Organized Formation of Polarized Cortical Tissues from ESCs and Its Active Manipulation by Extrinsic Signals. Cell Stem Cell. 2008;3(5):519-532. doi:10.1016/j.stem.2008.09.002

64. Gaspard N, Bouschet T, Hourez R, et al. An intrinsic mechanism of corticogenesis from embryonic stem cells. Nature. 2008;455(7211):351-357. doi:10.1038/nature07287

65. Gesundheit B, Ashwood P, Keating A, Naor D, Melamed M, Rosenzweig JP. Therapeutic properties of mesenchymal stem cells for autism spectrum disorders. Med Hypotheses. 2015;84(3):169-177. doi:10.1016/j.mehy.2014.12.016

66. Le Blanc K, Pittenger MF. Mesenchymal stem cells: progress toward promise. Cytotherapy. 2005;7(1):36-45. doi:10.1080/14653240510018118 


\section{www.ijsrm.humanjournals.com}

67. Beggs KJ, Lyubimov A, Borneman JN, et al. Immunologic consequences of multiple, high-dose administration of allogeneic mesenchymal stem cells to baboons. Cell Transplant. 2006;15(8-9):711-721. http://www.ncbi.nlm.nih.gov/pubmed/17269442. Accessed September 6, 2018.

68. Uccelli A, Moretta L, Pistoia V. Mesenchymal stem cells in health and disease. Nat Rev Immunol. 2008;8(9):726-736. doi:10.1038/nri2395

69. Petrie Aronin CE, Tuan RS. Therapeutic potential of the immunomodulatory activities of adult mesenchymal stem cells. Birth Defects Res Part C Embryo Today Rev. 2010;90(1):67-74. doi:10.1002/bdrc.20174

70. Sotiropoulou PA, Papamichail M. Immune Properties of Mesenchymal Stem Cells. In: ; 2007:225-243. doi:10.1007/978-1-59745-536-7_16

71. Newman RE, Yoo D, LeRoux MA, Danilkovitch-Miagkova A. Treatment of inflammatory diseases with mesenchymal stem cells. Inflamm Allergy Drug Targets. 2009;8(2):110-123. http://www.ncbi.nlm.nih.gov/pubmed/19530993. Accessed September 6, 2018.

72. Razavi S, Razavi MR, Zarkesh Esfahani H, Kazemi M, Mostafavi FS. Comparing brain-derived neurotrophic factor and ciliary neurotrophic factor secretion of induced neurotrophic factor secreting cells from human adipose and bone marrow-derived stem cells. Dev Growth Differ. 2013;55(6):648-655. doi:10.1111/dgd.12072

73. Drago D, Cossetti C, Iraci N, et al. The stem cell secretome and its role in brain repair. Biochimie. 2013;95(12):2271-2285. doi:10.1016/j.biochi.2013.06.020

74. Zheng G-P, Ge M-H, Shu Q, Rojas M, Xu J. Mesenchymal stem cells in the treatment of pediatric diseases. World J Pediatr. 2013;9(3):197-211. doi:10.1007/s12519-013-0425-1

75. Siniscalco D, Giordano C, Galderisi U, et al. Long-lasting effects of human mesenchymal stem cell systemic administration on pain-like behaviors, cellular, and biomolecular modifications in neuropathic mice. Front Integr Neurosci. 2011;5:79. doi:10.3389/fnint.2011.00079

76. Zemel'ko VI, Kozhukharova IB, Alekseenko LL, et al. [Neurogenic potential of human mesenchymal stem cells isolated from bone marrow, adipose tissue and endometrium: a comparative study]. Tsitologiia. 2013;55(2):101-110. http://www.ncbi.nlm.nih.gov/pubmed/23718072. Accessed September 6, 2018.

77. Siniscalco D, Giordano C, Galderisi U, et al. Intra-brain microinjection of human mesenchymal stem cells decreases allodynia in neuropathic mice. Cell Mol Life Sci. 2010;67(4):655-669. doi:10.1007/s00018-009-0202-4

78. Hoogduijn MJ, Popp F, Verbeek R, et al. The immunomodulatory properties of mesenchymal stem cells and their use for immunotherapy. Int Immunopharmacol. 2010;10(12):1496-1500. doi:10.1016/j.intimp.2010.06.019

79. Siniscalco D, Sapone A, Giordano C, et al. The Expression of Caspases is Enhanced in Peripheral Blood Mononuclear Cells of Autism Spectrum Disorder Patients. J Autism Dev Disord. 2012;42(7):1403-1410. doi:10.1007/s10803-011-1373-z

80. Kadri T, Lataillade J-J, Doucet C, et al. Proteomic study of Galectin-1 expression in human mesenchymal stem cells. Stem Cells Dev. 2005;14(2):204-212. doi:10.1089/scd.2005.14.204

81. Ryan JM, Barry FP, Murphy JM MB. Mesenchymal stem cells avoid allogeneic rejection. J Inflamm. 2005:2:8.

82. Liu J, Lu XF, Wan L, et al. Suppression of human peripheral blood lymphocyte proliferation by immortalized mesenchymal stem cells derived from bone marrow of Banna Minipig inbred-line. Transplant Proc. 2004;36(10):3272-3275. doi:10.1016/j.transproceed.2004.11.090

83. Tögel F, Hu Z, Weiss K, Isaac J, Lange C, Westenfelder C. Administered mesenchymal stem cells protect against ischemic acute renal failure through differentiation-independent mechanisms. Am J Physiol Renal Physiol. 2005;289(1):F31-42. doi:10.1152/ajprenal.00007.2005

84. Plumas J, Chaperot L, Richard M-J, Molens J-P, Bensa J-C, Favrot M-C. Mesenchymal stem cells induce apoptosis of activated T cells. Leukemia. 2005;19(9):1597-1604. doi:10.1038/sj.leu.2403871

85. Koç ON, Gerson SL, Cooper BW, et al. Rapid hematopoietic recovery after coinfusion of autologous-blood stem cells and culture-expanded marrow mesenchymal stem cells in advanced breast cancer patients receiving highdose chemotherapy. J Clin Oncol. 2000;18(2):307-316. doi:10.1200/JCO.2000.18.2.307

86. Liu W-P, Wang J, Qu S-Q, et al. [Transplantation of human neural precursor cells in the treatment of children with pervasive developmental disorder]. Zhongguo Dang Dai Er Ke Za Zhi. 2013;15(10):860-865. http://www.ncbi.nlm.nih.gov/pubmed/24131839. Accessed August 27, 2018.

Citation: Muhammad Awais et al. Ijsrm.Human, 2020; Vol. 16 (3): 78-106. 


\section{www.ijsrm.humanjournals.com}

87. Filosa JA, Bonev AD, Straub S V, et al. Local potassium signaling couples neuronal activity to vasodilation in the brain. Nat Neurosci. 2006;9(11):1397-1403. doi:10.1038/nn1779

88. Takano T, Tian G-F, Peng W, et al. Astrocyte-mediated control of cerebral blood flow. Nat Neurosci. 2006;9(2):260-267. doi:10.1038/nn1623

89. Kim JH, Kim JH, Park JA, et al. Blood-neural barrier: intercellular communication at glio-vascular interface. $J$ Biochem Mol Biol. 2006;39(4):339-345. http://www.ncbi.nlm.nih.gov/pubmed/16889675. Accessed September 6, 2018.

90. Ebrahimi-Fakhari D, Sahin M. Autism and the synapse: Emerging mechaisms and the mechanism based therapies. Curr Opin Neurol. 2015;28(2):91-102. doi:10.1097/WCO.0000000000000186

91. Chaboub LS, Deneen B. Astrocyte form and function in the developing central nervous system. Semin Pediatr Neurol. 2013;20(4):230-235. doi:10.1016/j.spen.2013.10.003

92. Bauman ML, Kemper TL. Neuroanatomic observations of the brain in autism: a review and future directions. Int J Dev Neurosci. 2005;23(2-3):183-187. doi:10.1016/j.ijdevneu.2004.09.006

93. Fortin DA, Srivastava T, Soderling TR. Structural Modulation of Dendritic Spines during Synaptic Plasticity. Neurosci. 2012;18(4):326-341. doi:10.1177/1073858411407206

94. Boissart C, Poulet A, Georges P, et al. Differentiation from human pluripotent stem cells of cortical neurons of the superficial layers amenable to psychiatric disease modeling and high-throughput drug screening. Transl Psychiatry. 2013;3(8):e294. doi:10.1038/tp.2013.71

95. Habela CW, Song H, Ming G-L. Modeling synaptogenesis in schizophrenia and autism using human iPSC derived neurons. Mol Cell Neurosci. 2016;73:52-62. doi:10.1016/j.mcn.2015.12.002

96. Kim T-G, Yao R, Monnell T, et al. Efficient specification of interneurons from human pluripotent stem cells by dorsoventral and rostrocaudal modulation. Stem Cells. 2014;32(7):1789-1804. doi:10.1002/stem.1704

97. DeBoer EM, Anderson SA. Fate determination of cerebral cortical GABAergic interneurons and their derivation from stem cells. Brain Res. 2017;1655:277-282. doi:10.1016/j.brainres.2015.12.031

98. Imaizumi Y, Okano H. Modeling human neurological disorders with induced pluripotent stem cells. $J$ Neurochem. 2014;129(3):388-399. doi:10.1111/jnc.12625

99. Prilutsky D, Palmer NP, Smedemark-Margulies N, Schlaeger TM, Margulies DM, Kohane IS. iPSC-derived neurons as a higher-throughput readout for autism: promises and pitfalls. Trends Mol Med. 2014;20(2):91-104. doi:10.1016/j.molmed.2013.11.004

100. Wang P, Mokhtari R, Pedrosa E, et al. CRISPR/Cas9-mediated heterozygous knockout of the autism gene CHD8 and characterization of its transcriptional networks in cerebral organoids derived from iPS cells. Mol Autism. 2017;8(1):11. doi:10.1186/s13229-017-0124-1

101. Aksoy I, Utami KH, Winata CL, et al. Personalized genome sequencing coupled with iPSC technology identifies GTDC1 as a gene involved in neurodevelopmental disorders. Hum Mol Genet. 2017;26(2):367-382. doi: $10.1093 / \mathrm{hmg} / \mathrm{ddw} 393$

102. Choi H, Song J, Park G, Kim J. Modeling of Autism Using Organoid Technology. Mol Neurobiol. 2017;54(10):7789-7795. doi:10.1007/s12035-016-0274-8

103. Tamburini C, Li M. Understanding neurodevelopmental disorders using human pluripotent stem cell-derived neurons. Brain Pathol. 2017;27(4):508-517. doi:10.1111/bpa.12517

104. Eiges R, Urbach A, Malcov M, et al. Developmental Study of Fragile X Syndrome Using Human Embryonic Stem Cells Derived from Preimplantation Genetically Diagnosed Embryos. Cell Stem Cell. 2007;1(5):568-577. doi:10.1016/j.stem.2007.09.001

105. Wen L-L, Chiu C-T, Huang Y-N, Chang C-F, Wang J-Y. Rapid glia expression and release of proinflammatory cytokines in experimental Klebsiella pneumoniae meningoencephalitis. Exp Neurol. 2007;205(1):270-278. doi:10.1016/j.expneurol.2007.02.011

106. Farina C, Aloisi F, Meinl E. Astrocytes are active players in cerebral innate immunity. Trends Immunol. 2007;28(3):138-145. doi:10.1016/j.it.2007.01.005

107. Ashwood P, Anthony A, Torrente F, Wakefield AJ. Spontaneous mucosal lymphocyte cytokine profiles in children with autism and gastrointestinal symptoms: mucosal immune activation and reduced counter regulatory 


\section{www.ijsrm.humanjournals.com}

interleukin-10. J Clin Immunol. 2004;24(6):664-673. doi:10.1007/s10875-004-6241-6

108. Okada K, Hashimoto K, Iwata Y, et al. Decreased serum levels of transforming growth factor-betal in patients with autism. Prog Neuropsychopharmacol Biol Psychiatry. 2007;31(1):187-190. doi:10.1016/j.pnpbp.2006.08.020

109. Vargas DL, Nascimbene C, Krishnan C, Zimmerman AW, Pardo CA. Neuroglial activation and neuroinflammation in the brain of patients with autism. Ann Neurol. 2005;57(1):67-81. doi:10.1002/ana.20315

110. Cohly HHP, Panja A. Immunological findings in autism. Int Rev Neurobiol. 2005;71:317-341. http://www.ncbi.nlm.nih.gov/pubmed/16512356. Accessed September 6, 2018.

111. Enstrom AM, Onore CE, Van de Water JA, Ashwood P. Differentail monocyte respnses to TLR ligands in children with autism spectrum disorder. 2010;24(1):64-71. doi:10.1016/j.bbi.2009.08.001

112. Silva SC, Correia C, Fesel C, et al. Autoantibody repertoires to brain tissue in autism nuclear families. $J$ Neuroimmunol. 2004;152(1-2):176-182. doi:10.1016/j.jneuroim.2004.03.015

113. Singer HS, Morris CM, Williams PN, Yoon DY, Hong JJ, Zimmerman AW. Antibrain antibodies in children with autism and their unaffected siblings. $J$ Neuroimmunol. 2006;178(1-2):149-155. doi:10.1016/j.jneuroim.2006.05.025

114. Vojdani A, O’Bryan T, Green JA, et al. Immune Response to Dietary Proteins, Gliadin and Cerebellar Peptides in Children with Autism. Nutr Neurosci. 2004;7(3):151-161. doi:10.1080/10284150400004155

115. Kozlovskaia G V, Kliushnik TP, Goriunova A V, Turkova IL, Kalinina MA, Sergienko NS. [Nerve growth factor auto-antibodies in children with various forms of mental dysontogenesis and in schizophrenia high risk group]. Zhurnal Nevrol $i$ psikhiatrii Im SS Korsakova. 2000;100(3):50-52. http://www.ncbi.nlm.nih.gov/pubmed/10758649. Accessed September 6, 2018.

116. Sweeten TL, Bowyer SL, Posey DJ, Halberstadt GM, McDougle CJ. Increased prevalence of familial autoimmunity in probands with pervasive developmental disorders. Pediatrics. 2003;112(5):e420. http://www.ncbi.nlm.nih.gov/pubmed/14595086. Accessed September 6, 2018.

117. Müller-Hilke B, Mitchison NA. The role of HLA promoters in autoimmunity. Curr Pharm Des. 2006;12(29):3743-3752. http://www.ncbi.nlm.nih.gov/pubmed/17073673. Accessed September 6, 2018.

118. Zilbovicius M, Meresse I, Chabane N, Brunelle F, Samson Y, Boddaert N. Autism, the superior temporal sulcus and social perception. Trends Neurosci. 2006;29(7):359-366. doi:10.1016/j.tins.2006.06.004

119. Cubells JF. Targeting the glutamate system in the treatment of autistic spectrum disorders. Curr Psychiatry Rep. 2007;9(2):131. http://www.ncbi.nlm.nih.gov/pubmed/17389122. Accessed September 6, 2018.

120. Sivanesan S, Tan A, Jeyaraj R, et al. Pharmaceuticals and Stem Cells in Autism Spectrum Disorders: Wishful Thinking? World Neurosurg. 2017;98:659-672. doi:10.1016/j.wneu.2016.09.100

121. Marchetto MC, Belinson H, Tian Y, et al. Altered proliferation and networks in neural cells derived from idiopathic autistic individuals. Mol Psychiatry. 2017;22(6):820-835. doi:10.1038/mp.2016.95

122. Zuiki M, Chiyonobu T, Yoshida M, et al. Luteolin attenuates interleukin-6-mediated astrogliosis in human iPSC-derived neural aggregates: A candidate preventive substance for maternal immune activation-induced abnormalities. Neurosci Lett. 2017;653:296-301. doi:10.1016/j.neulet.2017.06.004

123. Lee C-T, Bendriem RM, Wu WW, Shen R-F. 3D brain Organoids derived from pluripotent stem cells: promising experimental models for brain development and neurodegenerative disorders. $J$ Biomed Sci. 2017;24(1):59. doi:10.1186/s12929-017-0362-8

124. Bradstreet JJ, Sych N, Antonucci N, et al. Efficacy of fetal stem cell transplantation in autism spectrum disorders: an open-labeled pilot study. Cell Transplant. 2014;23 Suppl 1(1_suppl):S105-12. doi:10.3727/096368914X684916

125. Ichim TE, Solano F, Glenn E, et al. Stem Cell Therapy for Autism. J Transl Med. 2007;9(1):1-9. doi:10.1186/1479-5876-5-30

126. Panchision DM. Meeting report: using stem cells for biological and therapeutics discovery in mental illness, April 2012. Stem Cells Transl Med. 2013;2(3):217-222. doi:10.5966/sctm.2012-0149

127. Liu EY, Scott CT. Great expectations: autism spectrum disorder and induced pluripotent stem cell technologies. Stem Cell Rev. 2014;10(2):145-150. doi:10.1007/s12015-014-9497-0

128. Sharpe K, Di Pietro N, Jacob KJ, Illes J. A Dichotomy of Information-Seeking and Information-Trusting: Stem

Citation: Muhammad Awais et al. Ijsrm.Human, 2020; Vol. 16 (3): 78-106. 


\section{www.ijsrm.humanjournals.com}

Cell Interventions and Children with Neurodevelopmental Disorders. Stem Cell Rev. 2016;12(4):438-447. doi:10.1007/s12015-016-9667-3 